\title{
Nudging to Improve: Impact of Nudges on Students' Progress and Academic Performance
}

\author{
Fahad Azam ${ }^{1, *}$ Abida Shaheen ${ }^{2,}$ Khurram Irshad ${ }^{3,}$ Hania Ahmer $^{4}$ \\ ${ }^{1}$ Department of Pharmacology, Shifa Tameer-e-Millat University 1 \\ ${ }^{2}$ Department of Pharmacology, Shifa Tameer-e-Millat University 2 \\ ${ }^{3}$ Department of Physiology, Shifa Tameer-e-Millat University 3 \\ ${ }^{4}$ Shifa College of Medicine \\ *Corresponding author. Email: fahad.scm@stmu.edu.pk
}

\begin{abstract}
Nudge is a concept introduced by behavioral sciences to ameliorate the attitude and behavior of individuals by utilizing the concept of positive reinforcement. The execution of nudges in a targeted and proper way has the potential to induce motivation in learners by identifying and making amends in the potential learning gaps. The present study used repeated nudges for a targeted group of students who performed subpar in the summative assessment of an integrated module and followed their performance in repeated online formative assessments. The identified students were sent multiple nudges through social media in the subsequent module. The summative scores of these students during both modules were compared with the rest of the students of the same class. The mean score of the study participants showed a significant improvement in comparison to the mean score of the rest of the class at the end of the second module. A significant improvement in the attendance, MCQ score and the overall score of the nineteen students in the second summative assessment were observed after frequent nudging. Students responding more frequently to our nudges showed more improvement in overall scores and attendance as compared to the participants who were less responsive to nudges. Nudging resulted in significant consequential improvement in the summative scores and attendance in comparison to other students. Nudging could be an effective strategy to incentivize students and allow them to identify their weak areas and put more effort into their studies and hence improve grades.
\end{abstract}

Keywords: nudging, behavior, assessment, motivation.

\section{INTRODUCTION}

Nudging is a concept initially derived from behavioral sciences which can be applied to different areas including academia and medical education. Nudges in the form of positive reinforcement are different features of the choice architecture that predictably influence individuals' behavior and improve the attitude and behavior of individuals [1].

Continuous reforms are being introduced in medical education to ameliorate the performance of medical students in assessments to improve educational outcomes [2]. Students who perform below expectations in class may be discouraged by peer competition and class rankings and utilizing frequent nudges may improve the performance of underachievers. Nudges do not exert a direct influence on the intended outcomes and instead utilize cognitive processes leading to a vicissitude in behavior. Nudges can incentivize students to identify and improve their weak areas when executed properly. The recent advancements in communication technology have made it possible to nudge students frequently to help them focus more on their weak areas and track their improvement through continuous assessments $[3,4]$. 
The application of nudging has not been plenarily explored in medical education even though this concept is being implemented in multiple fields. Nudging has the potential to improve the motivation, habits and attitudes of students towards studies but this method is quite challenging as its implementation requires sustained behavioral change over a long period $[5,6]$.

As nudging is a relatively recent approach to modify the behavior of underachievers, further investigation is required to evaluate the effectiveness of its application in improving and evaluating students' performance. Presently, we have limited evidence regarding the application of nudging as a tool to modify learning behavior in Pakistani medical students. In that context, the present study was designed to explore the role of nudging on the performance of medical students in summative assessments.

\section{METHODOLOGY}

A cross-sectional study was conducted in Year III medical students at Shifa College of Medicine (SCM) from December 2019-January 2020. SCM has an integrated curriculum with longitudinally and vertically integrated themes included in different modules. Each academic year consists of different modules with several formative assessments throughout the module followed by a summative assessment at the end of the module.

A total number of thirty-eight participants scoring less than the average class score $(73.51 \%)$. were identified after the first module (Essentials of Medicine) summative assessment. Out of thirty-eight, nineteen students gave informed consent to participate in the present study. The participants were sent multiple timed nudges utilizing text messages during the subsequent cardiovascular module (CVS) and multiple online formative assessments were planned to track the progress of the students.

An analysis was done to compare the summative scores of the students with the rest of the class in the CVS end of modular summative assessment before and after nudging.

\section{RESULTS}

At the end of the first EOM module, the mean summative score of the study participants was significantly less than the summative scores of the rest of the class $(64.53 \pm 4.16$ vs $75.44 \pm 7.74 ; \mathrm{p}<0.001)$.

Multiple nudges were frequently sent to these students and feedback on their performance in formative assessment was provided and an improvement in the mean score was recorded at the end of the second module; the summative scores of both groups of students were almost similar at the end of the second module (74.34 \pm 4.45 vs $76.26 \pm 6.95 ; \mathrm{p}=0.89$ ) (Figure 1).

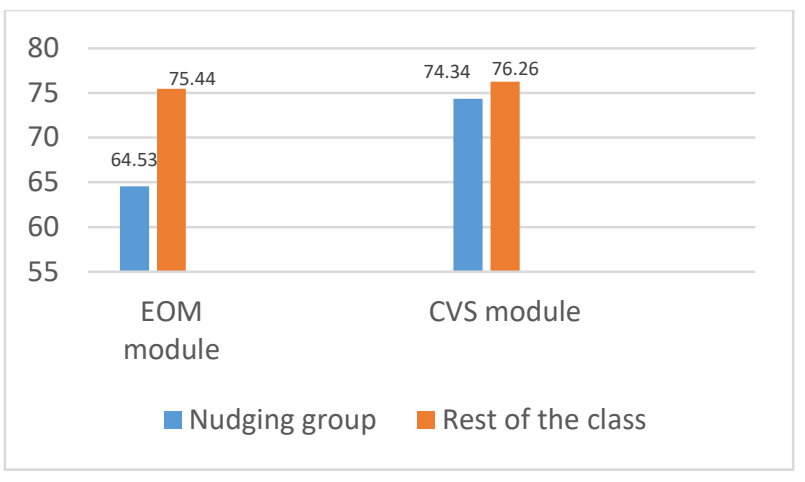

Figure 1: Summative scores comparison before and after nudging.

Significant consequential improvement was observed in the attendance and MCQs score of participants who were more responsive to frequent nudges during the second module as shown in Table 1.

\begin{tabular}{|l|l|l|l|}
\hline Variables & $\begin{array}{l}\text { EOM } \\
\text { module }\end{array}$ & $\begin{array}{l}\text { CVS } \\
\text { module }\end{array}$ & -value \\
\hline $\begin{array}{l}\text { End of } \\
\text { module } \\
\text { summative } \\
\text { score }\end{array}$ & $64.53 \pm 4.16$ & $74.34 \pm 7.74$ & $<0.001^{*}$ \\
\hline Attendance & $75.84 \pm 3.33$ & $85.58 \pm 7.65$ & $0.001^{*}$ \\
\hline
\end{tabular}

Table 1: Improvement in the end of module summative score and attendance before and after nudging

\section{DISCUSSION}

Educators all over the world are striving to explore various strategies to motivate underachiever students and improve their performance in assessments. Nudging is one of such various strategies which can improve both motivation and performance of students. [4,7].

The impact of nudging on the academic performance of medical students has not been explored before to the best of our knowledge. Our study showed an overall positive influence on the performance of medical students in summative assessments. After repeated and frequent nudges, significant improvement was observed in the summative scores of medical students who volunteered for the study and in the next module, their summative 
scores were statistically similar to the rest of the class. Our findings agree with the previous findings showing a positive impact of nudges on the overall performance of students; however, studies to explore the comparison of performance in the integrated curriculum have not been conducted yet $[8,9]$.

Significant improvement was observed in the performance of students in the nudging group in the summative assessments of the next integrated module $(\mathrm{p}=<0.001)$. This improvement in summative scores could be a direct consequence of the incremented motivation and more time spent on studies and one paramount factor could be the significant improvement in the attendance of students in the nudging group $(p=0.001)$. Our findings are in close agreement with other studies that have shown a significant change and improvement in attendance in students exposed to various nudging programs designed and implemented for behavioral modifications [10-12]. Our findings are also consistent with studies demonstrating a positive association of attendance with performance in assessments [13-15]. Other possible factors for the improvement in the scores could be the prelude of online tools and continuous reinforcement through digital mediums as research has shown that introducing digital tools can augment performance and interest in learning behavior [16-18].

\section{CONCLUSION}

One limitation of the present study is that we could not measure and analyse any difference in time spent on studies by students in the nudging group after the nudging intervention. We recommend future studies to explore the influence of nudging with a larger sample size and more variables such as sleep patterns, and changes in time spent on studies, social media and leisure activities.

\section{AUTHORS' CONTRIBUTIONS}

FA: Conceptualized and conducted study; collected, analyzed and interpreted data; drafted manuscript.

AS: Designed study; interpreted data and drafted manuscript; reviewed the final draft. KI: Designed study; analyzed and interpreted data; reviewed the final draft.

HA: Designed study; performed analysis and interpretation of data; reviewed the final draft.

\section{REFERENCES}

[1] R.H. Thaler, C.R. Sunstein, Nudge: Improving decisions about health, wealth, and happiness, 2008, London: Penguin
[2] M. Blumenstein, D. Liu, D. Richards, et al., Datainformed nudges for student engagement and success, PsyArXiv, 2018, pp. 1-25. DOI: https://doi.org/psyarxiv.com/qjmpn/

[3] R.J. Weijers, B.B. de Koning, F. Paas, Nudging in education: from theory towards guidelines for successful implementation, Eur J Psychol Educ, Springer, 2020.2 DOI: https://doi.org/10.1007/s10212-020-00495-0

[4] M.T. Damgaard, H.S. Nielsen, Nudging in education, Econ Educ Rev, Elsevier, 2018, 64, pp. 313-342. DOI:https://doi.org/10.1016/j.econedurev.2018.03.0 $\underline{08}$

[5] B. Szaszi, A. Palinkas, B. Palfi, et al., A Systematic Scoping Review of the Choice Architecture Movement: Toward Understanding When and Why Nudges Work, J Behav Decis Mak, Wiley Online Library, 2018, 31(3), pp. 355-366 DOI:https://doi.org/10.1002/bdm.2035

[6] D. Hummel, A. Maedche, How effective is nudging? A quantitative review on the effect sizes and limits of empirical nudging studies, J Behav Exp Econ, Elsevier, 2019, 80, pp. 47-58. DOI:https://doi.org/10.1016/j.socec.2019.03.005

[7] M. van Oldenbeek, T.J. Winkler, J. Buhl-Wiggers, et al., Nudging in blended learning: Evaluation of email-based progress feedback in a flippedclassroom information systems course, in: Proceedings of the 27th European Conference on Information Systems (ECIS), Stockholm \& Uppsala, Sweden, 2019, ISBN 978-1-7336325-0-8 Research Papers.

DOI:https://doi.org/aisel.aisnet.org/ecis2019_rp/18 62.

[8] D. Griffin, Nudging Students' Creative ProblemSolving Skills. PS: Political Science and Politics, JSTOR, 2011， 44(2), pp. 425-427. DOI:https://www.jstor.org/stable/41319930

[9] G.L. Sherr, S. Akkaraju, S. Atamturktur, Nudging Students to Succeed in a Flipped Format Gateway Biology Course, Journal of Effective Teaching in Higher Education, 2019, 2(2), pp. 1-13. DOI: https://doi.org/10.36021/jethe.v2i2.51

[10] R. Dreibelbis, A. Kroeger, K. Hossain, et al. Behavior Change without Behavior Change 
Communication: Nudging Handwashing among Primary School Students in Bangladesh, Int J Environ Res Public Health, 2016, 13(1): pp.129. DOI:https://doi.org/10.3390/ijerph13010129

[11] B.L. Castleman, L.C. Page, Summer nudging: Can personalized text messages and peer mentor outreach increase college going among low-income high school graduates?, Journal of Economic Behavior \& Organization, Elsevier, 2015, 115, pp. 144-160. DOI:https://doi.org/10.1016/j.jebo.2014.12.008

[12] T. Neuhaus, Nudging Education - The (Potential) Role of Decision Architectures in Improving Educational Setting, International Journal of Education and Research, 2020, 8(9), pp. 1-14.

[13] K.A.J. Al Khaja, Y. Tayem, H. James, et al., Pharmacology and therapeutics resource session attendance and academic performance of preclerkship medical students in problem-based learning curricula, BMC Med Educ, 2019, 19, 269, pp. 1-9. DOI:https://doi.org/10.1186/s12909-0191699-3

[14] R.P. Deane, D.J. Murphy, Student Attendance and Academic Performance in Undergraduate Obstetrics/Gynecology Clinical Rotations, JAMA. 2013, 310(21), pp. 2282-2288. DOI:https://doi.org/10.1001/jama.2013.282228

[15] B.S. Subramaniam, S. Hande, R. Komattil, Attendance and achievement in medicine: investigating the impact of attendance policies on academic performance of medical students. Annals of medical and health sciences research, 2013, 3(2), pp. 202-205. DOI:https://doi.org/10.4103/21419248.113662

[16] E. Galy, C. Downey, J. Johnson, The Effect of Using E-Learning Tools in Online and Campus-based Classrooms on Student Performance, Journal of Information Technology Education: Research, Informing Science Institute, 2011, 10 (1), pp. 209230.

[17] F. Azam, A. Shaheen, K. Irshad, et al., Trends of undergoing formative assessment in undergraduate medical students, JSTMU, 2019, 1(1): pp. 21 -26. DOI:https://doi.org/j.stmu.edu.pk/ojs/index.php/jst $\mathrm{mu} / \mathrm{article} / \mathrm{view} / 34$

[18] W.N.T. Wan Hussin, J. Harun, N.A. Shukor, Problem Based Learning to Enhance Students Critical Thinking Skill via Online Tools, Asian
Social Science, 2019, 15(1), pp. 14-23. DOI:https://doi.org/10.5539/ass.v15n1p14 